\title{
Application of coupons made of metal galvanic couples for corrosion monitoring and estimation of the efficiency of inhibitors
}

\author{
I.S. Sivokon ${ }^{1}$ (D) ${ }^{*}$ and E.I. Sivokon ${ }^{2}$ D \\ ${ }^{1}$ Gubkin Russian State University of Oil and Gas, Leninsky Pr., 65, 119991 Moscow, \\ Russian Federation \\ ${ }^{2}$ Northeastern University (undergraduate student), 360 Huntington Ave, Boston, MA \\ 02115, USA \\ *E-mail: issiv64@gmail.com
}

\begin{abstract}
Cylindrical coupons made of carbon steel with an offset potential and containing metallized inserts and coverings were gravimetrically analyzed. The analysis was carried out using steel 20 samples and 4 combinations of noble metals samples and alloys in models of formation water containing carbon dioxide with different concentrations of $\mathrm{NaCl}$. The influence of the presence of inserts in the cassette of cylinders made of noble metals and alloys on the background corrosion rate and the efficiency of the corrosion inhibitors (CI) was evaluated. Studies have shown that the presence of inserts made of more noble metals in the Coupons cassette increases the corrosion rate determined by the gravimetric method, and the efficiency of the CI significantly reduces. The obtained results indicate that there exists a field of application of coupons composed of various galvanic metal couples necessary for monitoring the effectiveness and selecting optimal dosages of CIs while taking into account measurements of the protective effect in areas with increased corrosion.
\end{abstract}

Keywords: galvanic metal couple, corrosion inhibitor, corrosion, gravimetric analysis, coupons, carbon dioxide, oil pipelines.

Received: June 19, 2021. Published: July 7, 2021

doi: $\underline{10.17675 / 2305-6894-2021-10-3-4}$

\section{Introduction}

Currently, the most common strategy for monitoring internal corrosion of oil pipelines (OP) is the gravimetric method. (GOST (Russian National Standard) 9.506-87 and GOST 9.50282). Regardless of the coupons types (cylindrical or strip), this method only measures general corrosion. There are particular studies and methods aimed at identifying and evaluating local corrosion on coupons. However, if to exclude laboratory measurements and separate bench tests, they have not received any wide application within the oil and gas industry.

Based on the results of corrosion measurements in the monitoring process, the efficiency is determined, and sufficient dosages of the implemented CIs are chosen to ensure the control and retention of the corrosion rate within the values that are safe for OPs [1,2].

The current practice of using gravimetric corrosion rate monitoring allows to base on it the decisions about the choice and recommended dosages of CIs. This actually leads to 
measurements of general corrosion with and without the CI being the main source of objective information needed for making important decisions related to the presence or absence of corrosion that is dangerous for the operation of OPs.

Alongside this, it is well known that the main cause of Ops' integrity disruptions (loss of leakproofness) is local corrosion and/or excessive general corrosion of distinct sections with a surface area from units to tens and hundreds of square centimeters. The dominant role of such corrosion damage to the OPs is also confirmed by the accident rate dynamics [3].

The presence of surface areas with a high corrosion rate in an OP can be associated with various reasons, but the mechanism and rate of the corrosion process itself are determined by:

- external conditions (temperature, pressure, flow rate, etc.);

-the composition of the corrosive medium (electrolyte solution);

-metal properties;

-the electrochemical potential of the metal in the electrolyte.

The gravimetric monitoring method with the installation of coupons inside the OP reproduces all the main criteria of corrosion quite well, with the exception of a number of factors that are both known and unknown, including the electrochemical potential. The key effect of "uncontrolled" factors on the measured corrosion rate is shown by a simple comparison of the results obtained by using different methods in the OP and in the laboratory [4]. While under the same conditions, the measured corrosion rate may differ by 10 or more times.

The problem of non-compliance of the monitoring results with the measurements of general corrosion with the actual data on the accident rate of OPs, the real, not the calculated efficiency of inhibitors, is significant. In the end, this is expressed in an increased accident rate and a reduction of the safe operation period of an OP. The underlying cause of "errors" and, as a result, problems with ensuring the operational reliability of OPs is the fact that, in the process of corrosion monitoring, it is not the general or local corrosion rate of the OP that is measured, but the general corrosion of the sensor placed in the fluids transported by the OP.

The consequences of inaccurate measurements of the corrosion rate of OPs are:

- unreasonable refusal or assignment of the usage of corrosion protection products;

- errors in evaluating the effectiveness of the applied CIs both when selecting for industrial use, and when determining a sufficient optimal dosage. According to GOST $55990-2014,{ }^{1}$ it is required to ensure a corrosion rate of no more than $0.1 \mathrm{~mm} /$ year for the ENTIRE surface of an OP, including the areas that are exposed to increased corrosion for any reason.

\footnotetext{
${ }^{1}$ According to the specified GOST, the corrosion rate of $0.1 \mathrm{~mm} /$ year serves as a criterion for whether or not corrosion protection is needed. Therefore, it is quite legitimate to extend this criterion to any type of corrosion observed or calculated for an OP. There is no indication that only general or uniform corrosion is taken into account in this GOST.
} 
The solution to the aforementioned problem can be to monitor the corrosion of OPs using coupons with a potential shifted to the anode region - how it is described in [5],

Where the principle of obtaining higher values of the corrosion rate on samples in comparison with the general corrosion is shown. The incompatibility is due to the displacement of the potential of coupons' surface into the anode region upon contact with a more noble metal. Ref. [5] presents coupons made of corrosion-active metals, which are made of the metal under research, and special coupons made of a metal placed to the right of the material under research in the reactivity series, while coupons and special coupons are placed next to each other and form galvanic pairs.

Thus, when coupons are installed into OPs, it becomes possible to answer the following questions:

- what can be the rate of corrosion due to the presence of anode zones, etc.;

- what will be the protective effect of the CI on such areas of the surface of an OP?

- what will be the protective effect of the corrosion inhibitor on the surface areas of the OP with increased corrosion?

The use of combined metal pairs as coupons allows to obtain different corrosion rates in a controlled manner using computational methods [6]. Thus, the method makes it possible to obtain a corrosion rate on the coupon similar to that observed on the OP according to nondestructive testing data or the actual accident rate.

This article presents the results of laboratory research on coupons with a shifted potential with various metal pairs, on which the background corrosion rate and the corrosion rate in the presence of IR were measured by the gravimetric method using a pre-determined effective concentration that provides a protective effect of more than $80 \%$ on standard coupons.

Research objectives:

- determine the change in the corrosion rate of coupons with a potential shifted to the anode region that are made of carbon steel, depending on the displacement of the electrode potential by means of contact with metallized inserts;

- determine the effect of the CI on the corrosion rate of anode samples made of steel in the cassette of coupons with a shifted potential (with cathode inserts).

The research was handled in a testing laboratory of Federal State-Funded Educational Institution of Higher Education "Ufa State Petroleum Technological University".

\section{The testing procedure}

The testing procedure consisted of determining the mass loss of coupons and coupons with a shifted potential and special inserts (coverings) after exposure in a model corrosion environment, both inhibited and not inhibited by reagents (corrosion inhibitors). 
The tests were conducted using the gravimetric method in accordance with GOST 9.506-87 and GOST 9.502-82. The tests were carried out on cylindrical samples. The mass loss of coupons made of steel 20 was determined.

For testing under dynamic conditions at the atmospheric pressure the Laboratory Aspirator Bottle (see Figure 1) was used. This setup ensures stable maintenance and control of test parameters during the test time in accordance with the given program, the constancy of the volume and composition of the test environment, the ability to blow the device with inert gas needed for deaeration and further saturation with carbon dioxide, the insertion of the inhibitor into the medium, and thermostatic control.

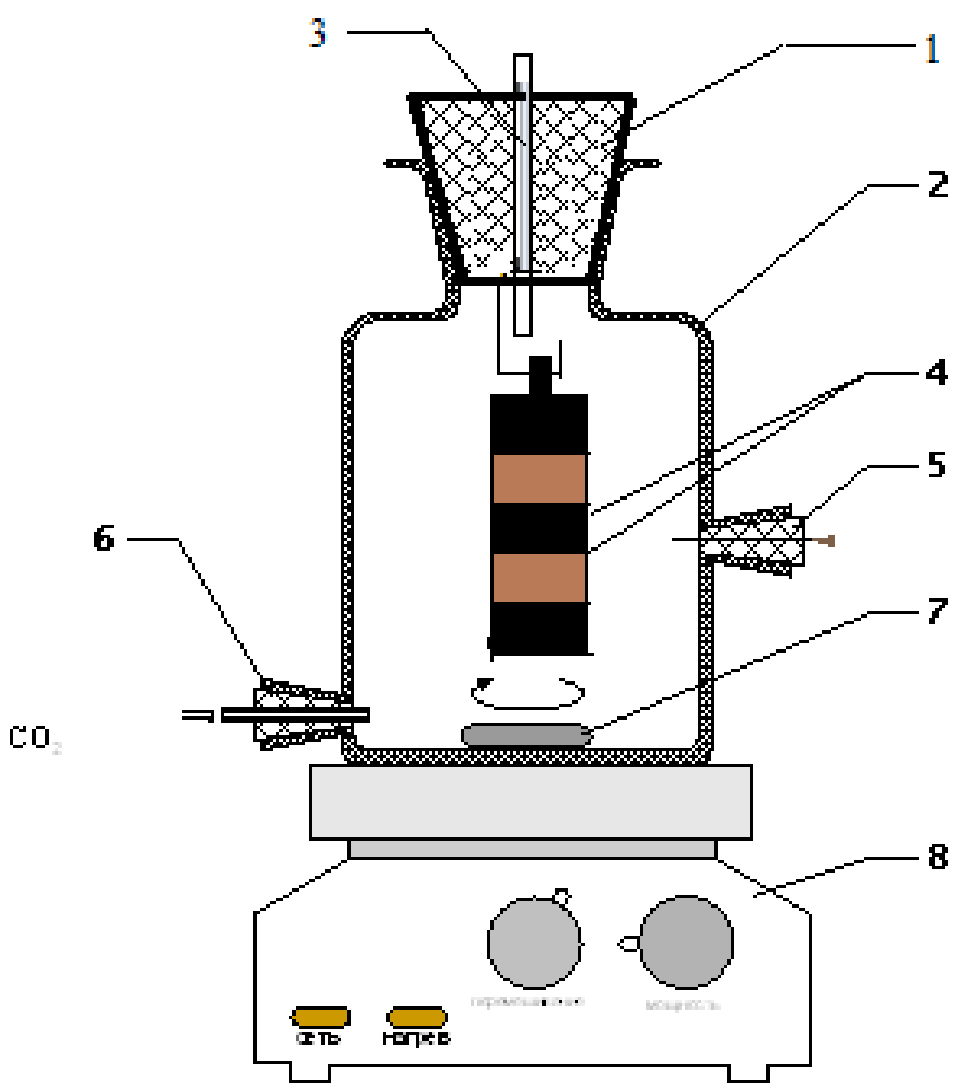

Figure 1. The setup (Laboratory Aspirator Bottle) in assembly: 1 - stopper; 2 - glass cell (variation of Laboratory Aspirator Bottle, volume of 3 liters) filled with a model of formation water; 3 -glass tube; 4 - cassette with steel cylindrical coupons; 5 - rubber stopper with a needle for injecting a corrosion inhibitor; 6 - rubber stopper with a tube for blowing carbon dioxide; 7 - mixing element (anchor); 8 - magnetic stirrer with adjustable heating.

The test samples were firmly fixed in the setup in order to protect them from vibration and to ensure free contact with the test medium.

The flow velocity of the test medium relative to the samples was $1.0 \mathrm{~m} / \mathrm{s}$. The structure of the setup provided free disassembly of components in contact with the test medium for washing them after testing and eliminating the possibility of developing contact and crevice 
corrosion between the samples, between the parts of the attachment of samples and samples, as well as between the walls of the apparatus and samples.

Before testing, the sample surface was ground to a roughness of no more than 1.6 microns according to GOST 2789-73 and degreased with acetone. The prepared samples were placed in the setup (see Figure 1) with the test medium. The test time was counted from the moment the samples were placed into the medium. The test lasted for $6 \mathrm{~h}$. Immediately after the tests, the samples were subjected to visual inspection to determine the presence and color of corrosion products, and, after removing the corrosion products, the nature of corrosion.

The trials were conducted on control samples made of steel 20 and four combinations of samples made of steel 20 with more noble metals and an alloys.

For doing the tests, the model of formation water that contains carbon dioxide was used. There were two compositions of formation water with different concentrations of $\mathrm{NaCl}$.

Composition of the formation water model No. 1:

$-\mathrm{NaHCO}_{3}-0.08 \mathrm{~g} / \mathrm{dm}^{3}$;

$-\mathrm{NaCl}-240 \mathrm{~g} / \mathrm{dm}^{3}$;

- the total content of salts dissolved in water: $240.08 \mathrm{~g} / \mathrm{dm}^{3}$;

Composition of the formation water model No. 2:

$-\mathrm{NaHCO}_{3}-0.08 \mathrm{~g} / \mathrm{dm}^{3}$;

$-\mathrm{NaCl}-24 \mathrm{~g} / \mathrm{dm}^{3}$;

- the total content of salts dissolved in water: $24.08 \mathrm{~g} / \mathrm{dm}^{3}$.

A membrane-forming water-soluble corrosion inhibitor with a dosage of $50 \mathrm{~g} / \mathrm{t}$ was taken. Such inhibitor provides a protective effect of more than $80 \%$ on standard (not combined) samples. The effect of the shift of the electrochemical potential on the effectiveness of inhibitory protection was evaluated.

The trials were conducted in the following sequence:

- The test cell (Laboratory Aspirator Bottle) was filled with a calculated amount of water; the water was saturated with carbon dioxide. Simultaneously, oxygen was removed from the water. The water temperature in the test cell was $50^{\circ} \mathrm{C}$.

- After complete removal of oxygen, the carbon dioxide flow rate was set to $5-8 \mathrm{~cm}^{3} / \mathrm{m}$.

- The rotation speed of the stirrer was brought to (540-560) $\mathrm{min}^{-1}$.

- Cylindrical coupons were used as an indicator of the corrosion rate.

The corrosion rate value on the control steel coupons (without inserts or coverings) obtained before the inhibitor was introduced was taken as the control corrosion rate (CCR).

The corrosion rate value on the control steel coupons obtained after the inhibitor was introduced was taken as the control corrosion rate in the inhibited medium (CCRI). 
In total, tests were carried out on 5 types of coupons: "control" - a standard cassette of 10 metal cylinders (steel 20); "combination 1-4" - a standard cassette of 10 metal cylinders, some of which are made of other, more noble metals, and/or with a galvanic metal coating. The area of each cylinder in the cassette was $508 \mathrm{~mm}^{2}$.

\section{Test results and their discussion}

The averaged results of gravimetric tests of cylindrical samples in the formation water model (composition No. 1 and No. 2) and calculations are presented in Table 1. The corrosion rate was calculated for the anode sample in the given combination.

Table 1. Summary table of the results of gravimetric tests of cylindrical samples in the formation water model (composition No. 1 and No. 2).

\begin{tabular}{ccc}
\hline Sample type & Composition No. 1, mm/year & Composition No. 2, mm / year \\
\hline control & 0.896 & 0.676 \\
combination 1 & 0.771 & 1.692 \\
combination 2 & 0.558 & 1.950 \\
combination 3 & 0.847 & - \\
combination 4 & 2.491 & 2.359 \\
\hline
\end{tabular}

Figure 2 shows a diagram of the corrosion rate of samples at different combinations and model compositions of water.

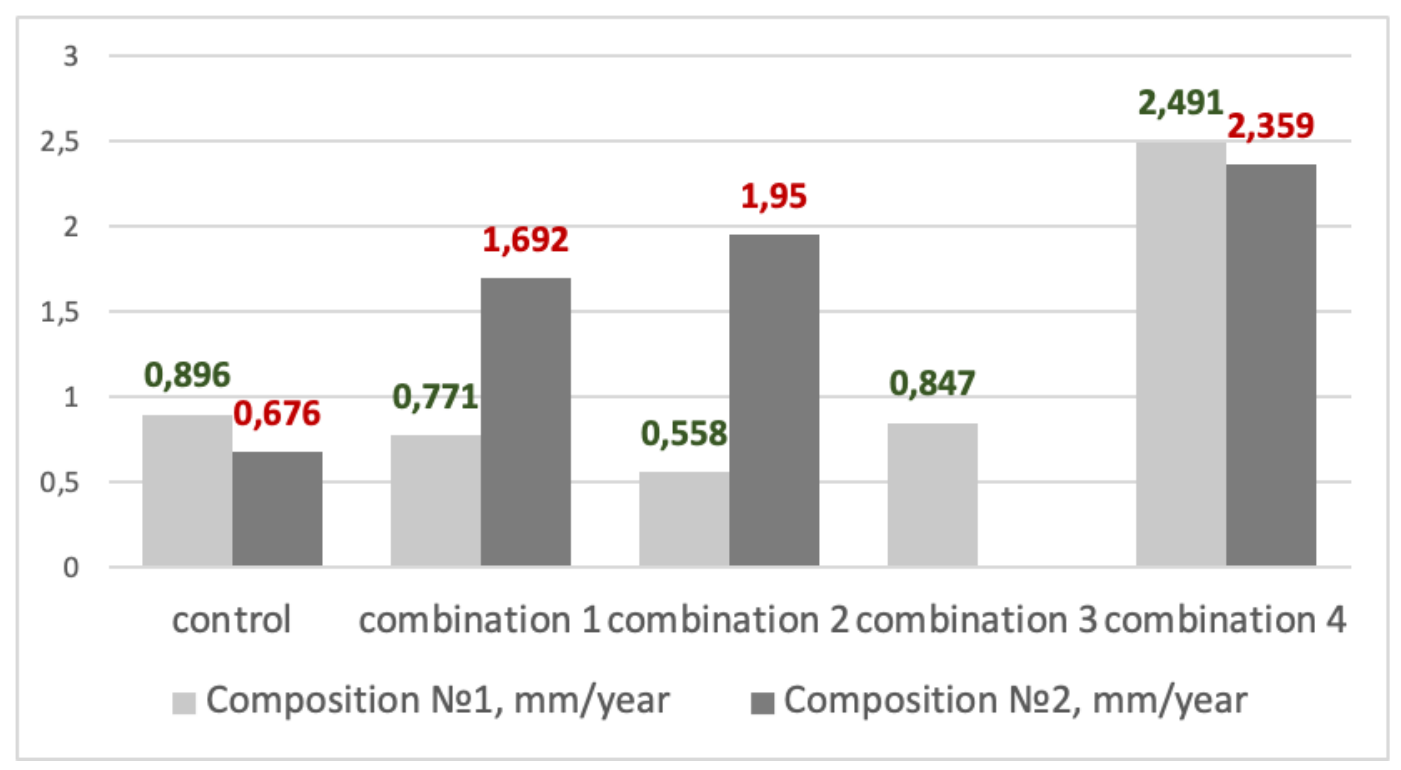

Figure 2. Results of gravimetric tests of cylindrical samples in the formation water model (compositions No. 1 and No. 2). 
Tests on composition No. 1 showed that on a standard cassette without inserts, steel samples became covered with a layer of iron carbonates caused by the presence of carbon dioxide (Figure 3). General corrosion was detected.
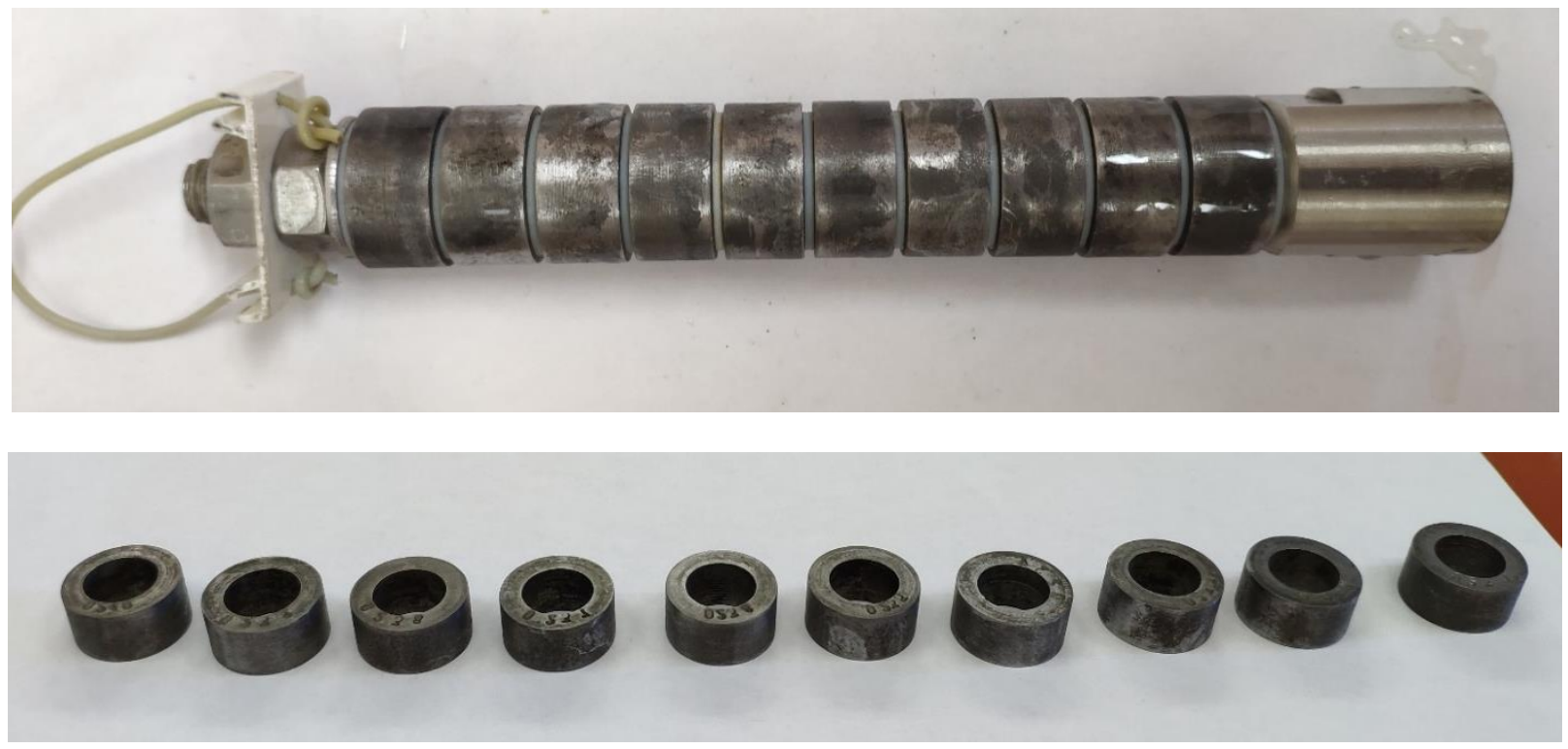

Figure 3. Samples of coupons after control cassette trials in the composition No. 1 of model water.

In addition, as shown in Figure 2 and in Table 1, for composition No. 1, the presence of contact with a more noble metal or alloy does not cause an increase in the mass loss of the samples. Correspondingly, the corrosion rate on the cassettes in combinations No. 1-3 did not increase. The exception is combination No. 4, which may be due to the use of platinum as a noble metal in this combination. At the same time, after testing on steel samples, the development of local types of corrosion - pitting and ulcerative - was observed (Figure 4).
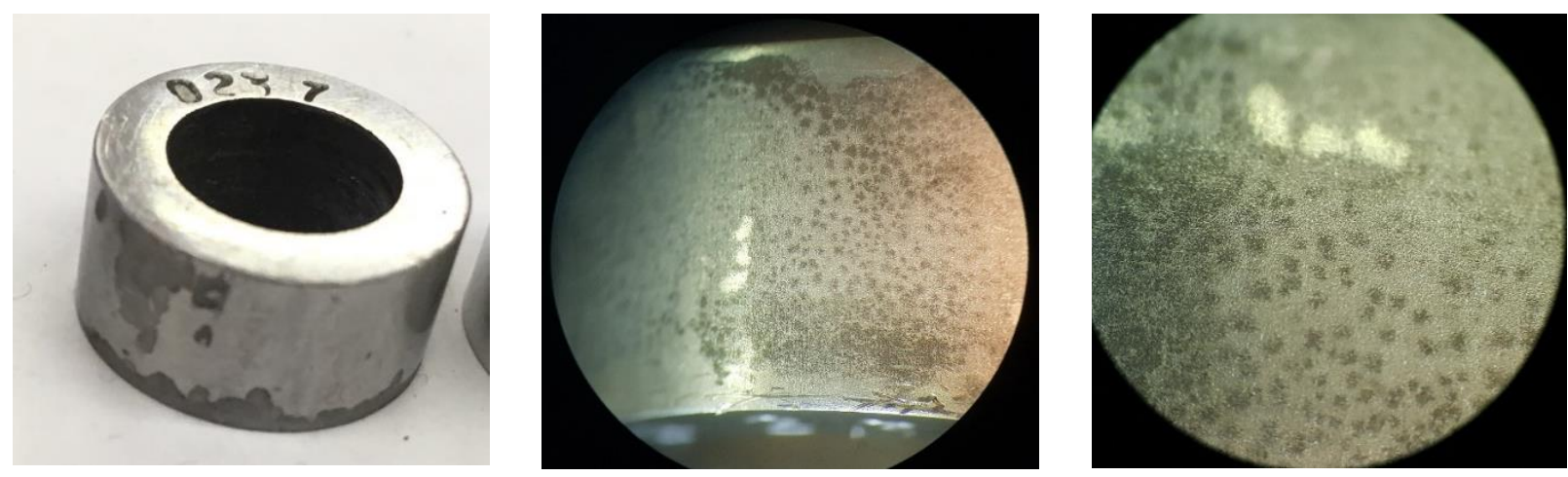

Figure 4. Local corrosion on steel samples in combinations No. 1-3 after testing in the composition No. 1 of model water. 
Similar trials on composition No. 2 of the model water revealed that a decrease in the chloride content provided a higher rate of corrosion of steel samples in various combinations (see Figure 2). However, the reference corrosion rate decreased by 1.3 times. At a lower concentration of chloride ions, there is a decrease in the corrosion localization on the metal surface (Figure 5).

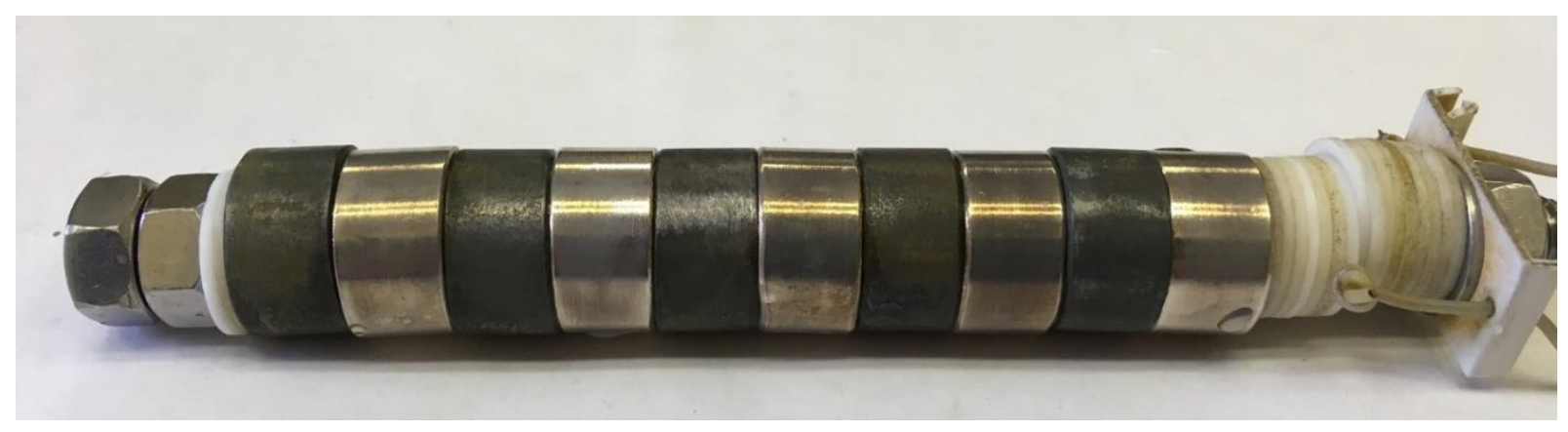

Figure 5. Samples of one of the tested combinations after gravimetric tests of cylindrical samples in the formation water model (composition No. 2).

Table 2 shows the results of gravimetric tests of cylindrical samples in the formation water model (composition No. 2) with and without a corrosion inhibitor. The corrosion rate was calculated for the anode sample in the given combination.

Table 2. Summary table of the results of gravimetric tests of cylindrical samples in the formation water model (composition No. 2) with and without a CI (50 g/t).

\begin{tabular}{cccc}
\hline Sample type & $\begin{array}{c}\text { Background corrosion } \\
\text { rate (composition } \\
\text { No. 2), mm/year }\end{array}$ & $\begin{array}{c}\text { Corrosion rate with } \\
\mathbf{5 0} \text { g/t of CI, mm/year }\end{array}$ & $\begin{array}{c}\text { Protective effect, } \\
\mathbf{\%}\end{array}$ \\
\hline control & 0.676 & 0.13 & 80.8 \\
combination 1 & 1.692 & 0.64 & 62.2 \\
combination 2 & 1.95 & 0.811 & 58.4 \\
combination 4 & 2.359 & 1.096 & 53.5 \\
\hline
\end{tabular}

Figure 6 shows a comparative diagram of the corrosion rate of steel 20 in an inhibited and non-inhibited medium in contact with noble metals and alloys. 


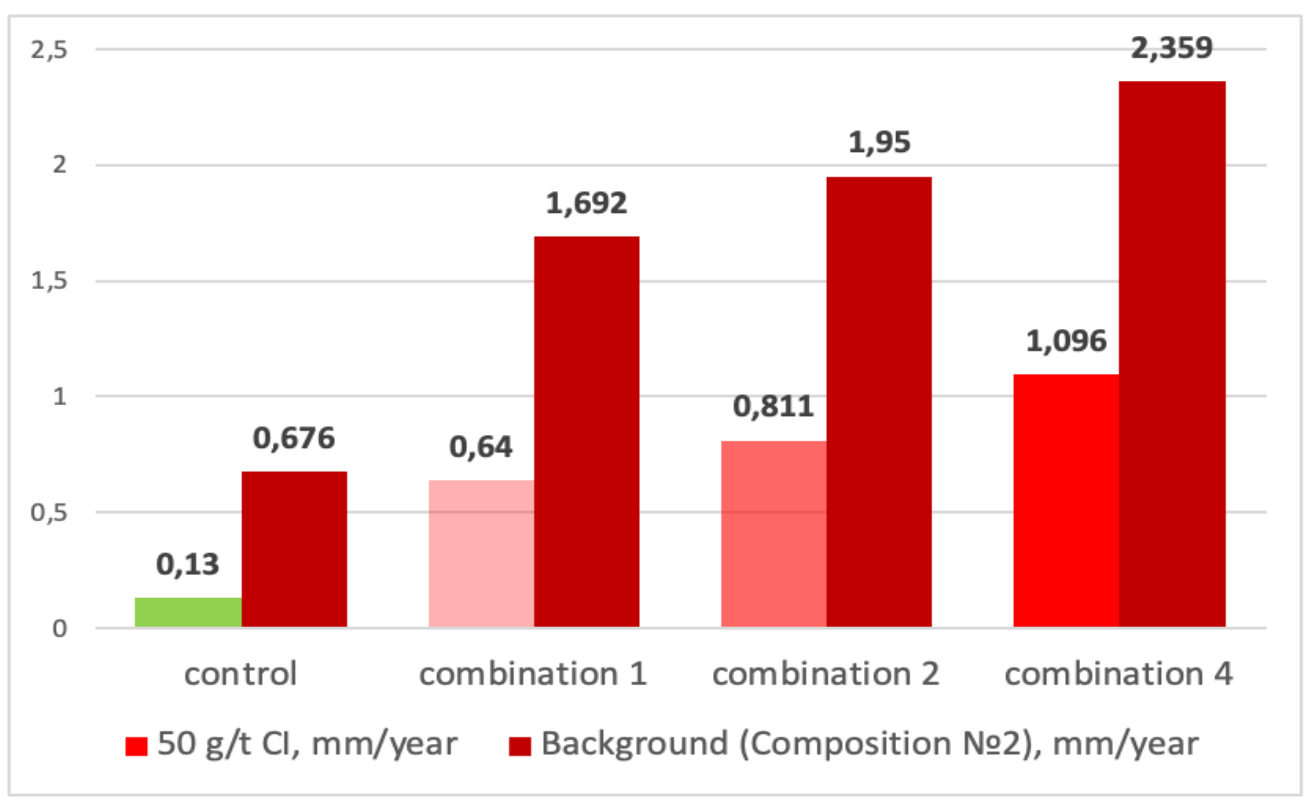

Figure 6. Results of gravimetric tests of the CI efficiency on cylindrical samples in the formation water model (composition No. 2).

The results of measuring the efficiency of the CI for reducing the corrosion rate of steel samples in various combinations (see Table 2 and Figure 6) demonstrated a significant reduction in the protective effect from $80.8 \%$ for the control cassette to $53.5 \%$ for the cassette with a combination of steel and platinum samples.

The reduction in the efficiency of the $\mathrm{CI}$ for conditions that simulate increased corrosion in combined cassettes is even more prominent if we pay attention to the corrosion rate itself, in the presence of the CI. If the control cassette has a remaining corrosion rate of only $0.13 \mathrm{~mm} /$ year, which in accordance with GOST 55990-2014 can be considered a completely safe level that ensures the safe operation of the OP, then, while in corrosion conditions with a shifted electrochemical potential on combined cassettes, the remaining corrosion rate for different combinations is in the range from 0.6 to $1.1 \mathrm{~mm} / \mathrm{year}$. Such corrosion rates, in the presence of the $\mathrm{CI}$ and with a formal protective effect of more than $80 \%$, already pose a great threat to the integrity of the OP with the resulting risks of breakdowns and a reduction in the safe operation period.

The result obtained in laboratory tests on coupons with a shifted potential - the rate of corrosion in the presence of an inhibitor in the range of $0.6-1.1 \mathrm{~mm} /$ year in areas with increased corrosion - well explains the fact that many OPs that have a wall thickness of 6 to $11 \mathrm{~mm}$ and are provided with inhibitory corrosion protection, with an efficiency of $80 \%$ or more measured by standard coupons (the rate of total corrosion of less than $0.1 \mathrm{~mm} / \mathrm{year}$ ), in practice, have through corrosion damages after 5-6 years from the beginning of exploitation, and in 10-12 years it is necessary to raise the question of their replacement due to the increasing and uncontrolled accident rate [7]. 


\section{Conclusion}

Gravimetric tests of coupons made of carbon steel with metallized inserts and coverings were carried out in an inhibited and non-inhibited model corrosion medium on the setup, which ensures stable maintenance and control of the test parameters over time.

The tests were run on samples made of steel 20 as well as on 4 combinations of samples with more noble metals and alloys in a model of formation water containing carbon dioxide of two compositions with different concentrations of $\mathrm{NaCl}$. A film-forming water-soluble corrosion inhibitor with a dosage of $50 \mathrm{~g} / \mathrm{t}$ was used. The influence of the presence of inserts in the cassette of cylinders made of noble metals and alloys on the background corrosion rate and the efficiency of the CI was estimated.

During the control test in the solution of composition No. 1, the steel samples were covered with a film of iron carbonates caused by the presence of carbon-acid gas. General corrosion was observed. However, the contact of steel 20 with a more noble metal or alloy did not cause an increase in the mass loss of the samples, except for the combination of No. 4 with platinum inserts. Simultaneously, after testing on steel samples, the development of local types of corrosion - pitting and ulcerative - was observed.

The reduction of the chloride content (composition No. 2) provided a higher corrosion rate of steel samples in various combinations, but the control corrosion rate decreased by 1.3 times. Decreasing the concentration of chloride ions led to lessening of the corrosion localization on metal surface.

The obtained results indicate that there is a need to review field methods for monitoring the effectiveness and selecting optimal dosages of corrosion inhibitors, taking into account the measurement of the protective effect in areas with increased corrosion. When using coupons, it is crucial to accurately model conditions of increased corrosion, for instance, by using inserts made of more noble metals.

Thus, the gravimetric method for determining the corrosion rate using coupons with a shifted potential can be used both for pilot-industrial tests of CIs and for routine monitoring of corrosion in order to control the efficiency of industrial CIs and determine the risks associated with the high corrosion aggressiveness of fluids transported through the OPs.

\section{References}

1. O.R. Latypov, Primenenie ingibitorov dlya zashchity neftepromyslovykh ob'ektov ot korrozii (Application of inhibitors for the protection of oilfield facilities from corrosion), Ufa, LLC Monografiya, 2016, p. 142 (in Russian).

2. O.R. Latypov, V.V. Kravcov and S.E. Cherepashkin, Teoriya i praktika zashchity ot korrozii truboprovodov $i$ rezervuarov (Corrosion protection of pipelines and tanks, theory and practice), Ufa, LLC Monografiya, 2018, p. 542 (in Russian).

3. I.S. Sivokon and N.N. Andreev, Regularities of oilfield leak rate variation in time, Int. J. Corros. Scale Inhib., 2014, 3, no. 2, 101-104. doi: 10.17675/2305-6894-2014-3-2-101$\underline{104}$ 
4. I.S. Sivokon, Otsenka tochnosti izmereniya skorosti korrozii razlichnymi metodami pri laboratornykh i promyslovykh ispytaniyakh ingibitorov korrozii (Evaluation of the accuracy of measuring the corrosion rate by various methods in laboratory and field tests of corrosion inhibitors), Praktika protivokorrozionnoj zashchity (Anticorrosive protection practices), 2014, 72, no. 2, 5-12 (in Russian).

5. Utility model No. 2018118852/28(029491) "Ustroistvo opredeleniya skorosti korrozii obraztsov" ("Device for measuring the corrosion rate of samples"), registration date: May 23, 2018.

6. I.B. Murashova, T.N. Ostanina and A.P. Hramov, Raschet korrozionnogo povedeniya kontaktnykh par metallov (Calculation of the corrosion-related behavior of metal contact pairs), Educational e-text edition, Ural State Technical University (UPI), 2005 (in Russian).

7. I.S. Sivokon, Povyshenie nadyozhnosti truboprovodov, podverzhennyh lokal'noi korrozii (Improving the reliability of pipelines exposed to local corrosion), Korroziya (Corrosion). Neftegaz territory, 2014, 5, pp. 36-42 (in Russian). 